wishing to acquaint themselves with some recent work on the pancreas, it has perhaps less special interest for paediatricians than other symposia in the same series.

Protein Metabolism. Influence of Growth Hormone, Anabolic Steroids, and Nutrition in Health and Disease. An International Symposium, Leyden, 25th-29th June, 1962. Edited by F. Gross. (Pp. xi +521 ; 159 figures + tables. DM. 37.50.) Berlin: Sprịnger-Verlag. 1962.

This volume comprises a series of interesting papers given at an international symposium on protein metabolism held in Leyden in June 1962.

Emphasis has been placed first on the action of hormones at the cellular level, and secondly on many aspects concerned with the mode of action and effects of anabolic steroids. Protein synthesis is effected by many hormones and in experiments described attempts have been made to elucidate the different ways in which growth hormone, testosterone, and oestradiol act on the cell.

Many of the papers are review articles, and those concerned with the clinical use of anabolic steroids will be particularly welcomed by the paediatrician dealing with growth disorders in childhood. It is disappointing, but perhaps not unexpected, that Professor A. Prader has concluded in an excellent review of his work that the growth-promoting effect of anabolic steroids is dependent not only on dosage and duration of treatment, but upon various endogenous factors. He thought it unlikely that these substances led to any increase above the expected adult height. Many clinicians, too, will be interested in the Danish experience in anabolic steroids in the treatment of renal failure and the opinion given on the effect of these substances on liver function.

This book is well produced; the text is in English, but summaries in German and French are given at the end of each paper. In addition, there are useful lists of references.

This authoritative book can be highly recommended, and much of it will be of great interest to the clinician.

Poisoning. Chemistry . . . Symptoms . . . Treatments. By JAY M. Arena. (Pp. xvii +440 ; illustrated. \$16.75.) Springfield, Illinois: Charles C. Thomas. 1963.

A book on poisoning by a Professor of Paediatrics naturally concentrates on poisoning in children: indeed, a graphic frontispiece illustrates this 'the most frequent paediatric emergency that exists today', and the author stresses his own deep personal concern with it.

One difficulty is that a relatively small subject, however important, when expanded to a book weighing $2 \mathrm{lb} .12 \mathrm{oz}$. must involve a certain leisureliness, if not padding. There is great virtue in completeness, but the inclusion of linseed oil ('digestible and nutritious, ingestion in large amounts is laxative') hardly merits inclusion, and neat's-foot oil, although used in America apparently to soften and waterproof leather, certainly was, and very likely still is, one of the commonest cooking fats in the Midlands of this country.
On the other hand, although black and blue nightshades, the relatively harmless solana, are included (and illustrated), there is only the briefest mention of atropa belladonna. There is naturally a good deal on local hazards, from the inevitable black widow spider to various strange plants. The highly American-poison at titude of the book is not an adverse criticism: the book is meant for America; but it detracts from its appeal in England. Very little is said about ferrous sulphate (and it is not mentioned as such in the index), but although "colouring and candy-coating' are mentioned, presumably American children are not subjected to the frightful risk of poison disguised as delicious sweets to which English children are so lethally liable.

Phenobarbitone, also, which is an all too common poison in this country, is apparently no trouble at all in America: its use in the treatment of other poisoning is given in detail but the comment on it as a poison is the shortest in the book, a line and a half.

Another objection is that the book is very weak indeed on the problem of identification of the exact poison while the patient is still alive, and it would be particularly irritating to a physician struggling to save a child poisoned by an unknown agent to read that at least half the brain should be sent for analysis. But this objection is not altogether fair: all books are poor on this subject. But there is a way out of this impasse: to concentrate on treating the processes by which a poison is killing the patient, rather than to bother over the exact substanceidentification and the exhibition of specific 'antidotes', and this aspect of treatment is not sufficiently stressed. The book is much better at enabling the nonplussed physician to tell a mother what to do when she complains that her son has just eaten a tri-ogen rose bomb, or when she thinks her husband, who is a straw-hat maker, is being poisoned by something in the factory.

It is hardly a condemnation of this book to say that it is not the ideal one for this country: in so far as the natural history or social habits of countries differ, books on toxicology must of necessity be best for the country for which they are written.

Artificial Respiration: Theory and Application. Edited by JAMES L. WhitTENBERGER. (Pp. $x+276$; 104 figures. $\$ 10.00$. 80s.). New York and London: Hoeber Medical Division, Harper and Row. 1962.

The editor states in the preface: 'The aim of this book is to present current concepts of the common methods of artificial respiration along with the practical and physiological considerations on which their use is based.'

After World War II the possibility of chemical warfare stimulated a considerable amount of research in the United States of America into resuscitation. After much testing of various methods of artificial respiration, one of the oldest methods was found most effective under nearly all circumstances-the mouth-to-mouth method.

The evidence for the superiority of this method and the demonstration of its feasibility are given as the main reasons for the timing of this book. 
The subject is dealt with in three parts: Part I, The Physiology of Respiration, is lucid and occupies 25 pages. Part II, Techniques of Artificial Respiration, occupies two-thirds of the book. In these chapters, all forms of artificial respiration are described and the shortcomings of each method are emphasized. The superiority of mouth-to-mouth methods is convincingly shown. This section also includes a chapter on closed-chest cardiac resuscitation. Part III, Clinical Artificial Respiration, includes a variety of conditions; barbiturate poisoning, carbon monoxide poisoning, drowning, paralytic poliomyelitis and anticholinesterase poisoning.

This book is well written and very well illustrated, the latter no doubt accounts largely for the relatively high price. It should be read by all members of the medical profession who may be faced with a patient requiring artificial respiration.

Die Krankheiten des Neugeborenen und Frühgeborenen. By S. Berlin-Heimendahl. (Pp. 540; illustrated.) Stuttgart: Ferdinand Enke. 1960.

This book has just over 500 pages with excellent pictures and $x$-ray photographs. This author has had 14 years' personal experience in Munich with the care of the mature and premature newborn, and she has worked in close association with a maternity unit.

The book is divided into two parts: the first deals with conditions in the mature newborn; and the second part deals with those occurring in the premature, including the criteria of prematurity.

The book is most enjoyable.

Applied Audiology for Children. By D. M. C. DALE. (Pp. xii $+165 ; 40$ figures. \$7.50.) Springfield, Illinois: Charles C. Thomas. 1962.

This book is written by an enthusiastic expert in testing the hearing of children and in fitting them with hearing aids, and is full of practical advice. The charts and illustrations are good.

The first chapter deals with the nature of sound and its amplification and explains clearly the principles upon which hearing aids are constructed. Theoretically a hearing aid should be designed for the individual deaf ear and make up its deficiencies on each frequency, but it has been found that the best response is got from aids with a level amplification with tone control and ability to boost the higher frequencies. They should cut off the peaks of sound and not produce anything over 4,000 c.p.s.

The instructions for testing young children for pure tones on the audiometer, and for speech, show that the author has great experience with children and sympathy for them. The audiograms showing various typical curves of hearing loss are discussed in a practical manner indicating the need for hearing aids, special education and the prospect of speech development. It is suggested that a hearing aid should be given an extended trial even with children who have more than $95 \mathrm{~dB}$ loss. About $30 \%$ of children in deaf school fall into this category.
There is a section on speech and its production, and upon the best listening environment and listening level. It is obviously difficult for a young deaf child to adjust his aid to the best advantage, and the writer very sensibly pleads for aids that are more clearly calibrated so that once the best amplification level has been ascertained it can be reproduced at will.

The proper fitting and care of aids are important matters to the deaf, and are very much more difficult in the child than in the adult. There is good practical advice about this and also on how to get a child to accept his aid, and wear it all the day-time. The continuous use of an aid is much more valuable than periods of intensive instruction.

The Bibliography and long list of References show that the author is widely informed on his subject, and the book demonstrates that he has a practical turn of mind. The result is a most useful book for those who work in this difficult field.

\section{Epidemiology and Genetics of Mental Deficiency in a} Southern Swedish Population. By Hans Olaf Åkesson. Translated by Robert N. Elston. (Pp. 107; 4 figures + 42 tables.) Sweden: Institute for Medical Genetics, The University of Uppsala. 1961.

This monograph describes a very thorough investigation of the incidence of mental deficiency in 10 rural parishes selected at random from 212 such families in a particular county. The total population included was about 7,500. All the usual sources of information were utilized and in addition a wide variety of informants supplied particulars about those thought to be even rather slightly retarded. A screening procedure was adopted and then those who could possibly come into the category of feeble-mindedness were tested on the Binet Scale. It is evident that very few mentally defective persons can have escaped the net, and this was confirmed by a large-scale control study.

The author uses limits of Binet I.Q. for defining the three grades of mental deficiency, namely feeble-mindedness, imbecility and idiocy. To facilitate comparison with other studies these limits were calculated in units of the standard deviation, namely $-2 \cdot 01$ to $-3 \cdot 00$ standard deviations, -3.01 to $-5 \cdot 00$, and -5.01 upwards, respectively. This corresponds to upper limits of approximately $70 \mathrm{I} . \mathrm{Q}$. (more precisely 68), $50 \mathrm{I} . \mathrm{Q}$. and 20 I.Q. for the three categories.

The incidences given refer to the population over 10 years of age. The averages for all 10 parishes are: feeble-mindedness $1 \cdot 2 \%$; imbeciles $0.5 \%$; idiots $0.1 \%$. The parishes were significantly heterogeneous and the one factor that stood out in this connexion was a relation to migration out of the parish: the higher the rate of emigration, the higher the proportion of mental deficiency in the population remaining. This is a finding that has frequently been noted in other investigations.

There was a tendency for the marriage rate to be distinctly low for feeble-minded men, whereas feeble- 